\title{
Research of Humanized Design of Urban Bus Station
}

\author{
Wenjun Wang ${ }^{1, a^{*}}$ and Hongxing $\mathrm{Yi}^{1, \mathrm{~b}}$ \\ ${ }^{1}$ City College of WUST, Wuhan, China \\ aWangwenjun2016hy@163.com, ${ }^{b} Y$ ihongxing2016hy@163.com
}

Keywords: Bus station; Humanized design; Optimization design; Barrier free design

\begin{abstract}
Bus station is a part of urban facilities and an indispensable important link of urban transport system as well. The design of it directly affects the daily life of everyone in the city. This paper, from the perspective of humanization, and taking Wuhan City as an example, studied the design of bus station in the city, and proposed a variety of design basis and methods for consideration to provide a convenient and green commuting for citizens.
\end{abstract}

\section{Introduction}

At present, the material life of urban people in China is unceasingly improved; however, the traffic problem is getting more seriously along with it, which holds negative implications of the daily life in the city. Economic and environment-friendly public transportation can effectively relieve the traffic congestion, but the existing design of bus station is inconvenient in using, which reduces people's enthusiasm in Green Commuting, and decreases the efficiency of public transportation system. Therefore, it is necessary to study the humanized design of bus station to encourage the use of public transportation in the city.

\section{Existing Situation}

Nowadays, people's requirements of urban environment are getting higher and higher. The traditional bus station was just a small sign board to locate the bus stops. As time goes by, after meeting its basic function of road signage, it developed itself into a multi-functional and intelligent one that fulfills a higher spiritual requirement of people.

The existing bus station in China has achieved its basic and practical function with proper aesthetics. But there is room for improvement especially in how to get it combined with the unique urban landscape. Most design of bus station in China, at present, ignored the reginal and cultural characteristics of different localities. The Su Zhou Bus Station, however, is an exception. It is exquisite and antique, and its imitation of wood appearance decorated with red lanterns perfectly matches the scenery of Suzhou, the ancient town. Meanwhile, the design of a bus station should be more human-oriented, and so as to build a convenient public facility, create a comfortable waiting environment, increase the frequency of utilization and make people love the idea of Green Commuting.

\section{Existing Problems}

In Wuhan City, the existing bus stations are still of great inconvenience. For example, some bus stations do not have disabled ramp, and is not humanized designed. The details are rough and the supporting facilities are not well equipped.

The problem of non-humanized design seems particularly outstanding. Being an urban public facility, the key point of the design should meet the demands of all the people. But the lack of disabled ramp, braille bus-stop board and voice prompt function shut its door on the blind people and people in wheelchair or pushing prams. Barrier free design is for these disabled people, and to create a safe, caring, loving, convenient and comfortable modern living environment. It is a reflection of social morality, and a symbol of spiritual civilization of a city and a country.

The structure of bus station details is rough and the supporting facilities are not well equipped. 
For example, Wuhan is a city of harsh weather, it is cold in winter and very hot in summer, but the roof of bus station is quite small and there is no downpipe system on it. So, when it rains, it becomes crowed, wet and moist, and in summer, it is unable to provide a proper shady space for passengers, and then people has to hide themselves behind the back of the bus station board, taking up the non-motor vehicle lanes or sidewalks. Also, the bus station is not well equipped with supporting facilities such as public telephone. Although everyone has a mobile phone today, but sometimes one may forget to take his phone, or the phone may be power off, under these circumstances, the public telephone is very important then.

In addition, the existing bus station in China lacks unique reginal characteristics. As mentioned before, the design of bus stations in Suzhou respects the ancient town style of the city, and blends naturally in the local environment. Local people and tourists get really impressed about it. The bus station provides a comfortable waiting environment, also highlights the city's unique feature, and set a favorable image of the city. How to build a bus station that can reflect the special reginal features in Wuhan? It is still a question need to be deliberated.

\section{The Methods of Humanized Design}

The current bus station design focuses on environment landscape. It is regarded as an appendant of a city in external space. Mainly uses the research methods of functional classification. It divides the station into several parts according to its functions, such as resting, lighting, public information, and guidance function. It is not human-oriented designed.

\section{Physical Property}

The natural environment is the objective material basis of a city. Wuhan is a typical subtropical inland city with numerous lakes, and the scenery in four seasons is quite distinctive. It is cold in winter and very hot in summer. So, the high saturation colors and warm colors of red, orange and yellow are not suitable to be used to avoid making people feel hot and "angry" in the summer season. As in winter, Wuhan is cold and wet, therefore, the color which is too cold or makes people feel depressed should not be used neither. For instance, terrace gardens in Italy have few bright-colored flowers, it is because the climate there is quite hot, and a large area of green can effectively lower the temperature psychologically.

Material is an important factor to the external forms of the bus station. In choosing the material, the primary element that we should bear in mind is that the bus station is an outdoor facility, therefore, durable, fire prevention; moisture-proof and easy-to-clean materials are preferred. It should also meet the requirements of modern technology and be easy to assemble and to maintain in daily use. Besides, the quality grade of the material should also be considered as the bus station is the reflection of city image.

The bus station should set a barrier-free ramp for the convenience of disabled persons. On the platform, we could use different colors in pavement to separate the zones of waiting and drop off area, and lead the streams of passengers to avoid making the platform a crowded and chaotic space.

A simple and monotonous appearance of a bus station is easy to cause ascetic fatigue. Waiting bus in this kind of station people are easily getting anxious and agitated as time goes by. The process of waiting seems much longer than it is. On the other hand, if the bus station is in human-friendly design, it can relieve the anxiety and uneasiness of people, minimize the waste of time, maximize the use of space, and meet people's different emotional release. As Wuhan is cold in winter and hot in summer, install cooling and heating equipment in the station will undoubtedly provide a comfortable waiting area for the people in harsh weathers.

The design of the bus station's roof should considerate the local climate and reginal features. In the city with plenty sunshine, set a solar roof is a good choice. It can produce green energy and makes the bus station more environmental friendly. Also, we could utilize the roof greening method to create a "sponge" to absorb the rainwater. Meanwhile, the basic function of the bus station should be fully considered as well, such as the roof drainage function. The design should not let the rain 
directly drop to the passengers or onto the platform, which will make the station even more damp and crowded. In summer, the design of the roof should guarantee to provide enough shadow area for the people, and avoid exposure.

\section{Usability}

As a commonly used public facility, the scale of a bus station should be reasonable and be comfortable, safe and convenient in using. The design could take a reference to the data of the science of human body engineering to provide comfortable feelings to the people. While, for its safety, we should consider fully of all the unsafe factors to avoid any potential risks. Then, for its convenience, the station should satisfy various requirements of different kinds of passengers. Humanized facilities should be included, such as barrier-free design, voice prompt facility and braille bus stop board and so on. Then it will be more convenient for all the passengers, the old, young and disabled.

Every citizen shall have the right to enjoy the outdoor space in the city, and it is also a basic and original intention for the barrier-free design, as the disabled, elderly and children are also the users of a bus station. For the man in wheelchair, pushing a pram or carrying a large luggage, a disabled ramp seems extremely important, while for the blind people, braille stop board and voice prompt facility is quite helpful. All these humanized design facility expresses the love and caring to the vulnerable groups in society and it is also a reflection of social progress and civilization.

Install a prompt equipment helps keeping the order in the platform. Combine the traditional bus station with the LED display device to provide the latest information of the bus to the passengers. It may effectively reduce the overcrowding in the platform.

If people are not able to obtain the effective information of the bus, they may not handle it properly, and can be easily haunted with negative emotions while waiting and even get angry at last. The design of the bus station's board should be simple and concise. The writings on the board should be easy to read and in appropriate font size. The board shouldn't be put too high or too low to make sure both adults and children are able to read. In addition, we can bring in the idea of classification in board design. It helps the passenger get the information more rapidly in visual, for example, in Wuhan there are three districts that are Wuchang, Hankou and Hanyang, and then we can use three colors to represent these districts.

LED screen can provide the track of the bus in real time which effectively relieves the anxiety of the passengers while waiting. Without it, people will pay close attention to every bus that arrives at the station and get nervous easily; or some people may use their cell phone chatting on line while waiting and miss the bus they are waiting. So, in roof designing, we consider to install a LED screen at the front where everyone can see it. Besides, we can also set a built-in speaker inside the roof broadcasting announcement when bus arrives. Therefore, the bus station can remind the passengers both visually and auditory.

Billboard is now an indispensable part of a traditional bus station, and it always covers a large area, thus there isn't enough space for other supporting facilities. The design of the bus station should be based on humanization; we can integrate the advertising facilities with the supporting ones. For example, at the back of the advertising board, we can install a touch screen. So, tourists or people that are not familiar with the route can get the information of bus route, traffic transfer and mapping conveniently. Mobile phone charging device can also be included for passengers' convenience, as they can charge their phone while waiting.

Different passengers may have different needs. After researching and studying, we get a conclusion that when designing a bus station, we should integrate its basic function with supporting facilities, such as public telephone, kiosk, exchange and vending machines. Today, the science and technology in society are developed rapidly, everyone has a cellphone, but people may forget to take his phone out or the phone is power off, so under these special circumstances, a public telephone will be quite helpful then. Bus card and IFC payment are very popular, but some people still prefer the traditional way of bus commute, so we should not ignore the needs of them and provide an exchange machine. Newspaper reading, food and beverages are the best partners while 
waiting a bus, therefore at the beginning of the design, the kiosk and vending machine should be taken into account as well.

\section{Locality}

Urban color is highly affected by its history and culture, and different cities and countries have a different understanding and interpretation even to the same color. Each city will form its unique urban color based on its own history development, religion and culture. Bus station as a landscape, is the window and name card of the city. The unique and distinctive design of it with profound cultural connotation will effectively improve the image of the city.

\section{Conclusion}

Bus station is a public facility, and a start or a passage to the next station. It is a natural, diverse and dynamic life stage. The design of it should be related to space art and be human-oriented. Meanwhile, like all the other designs, it is not just a design of an object, but a design of a safe, convenient and comfortable environment for people to enjoy.

\section{References}

[1] Robert Cervero: The Transit Metropolis (China Architecture \& Building Press, CHN 2007), p.98.

[2] J.Zhang, W.Q.Li, B.Ran: Intelligent programming and optimization method for the traffic planning of the conventional public transport vehicles (Southeast University Press, CHN 2014), p.121

[3] Anthony A. Saka: Journal of Transportation Engineering, Vol. 127 (2011) No.3, p.195.

[4] Rodrigo Fernandez: Traffic Engineering and Control, Vol. 21 (2001) No.9, p.240.

[5] S.C. Wirasinghe, Nadia S. Ghoneim: Transportation Science, Vol. 15 (1981) No.3, p.210.

[6] Vukan R.Vuchic: Urban Transit:Operations, Planning, and Economics (China Railway Publishing House, CHN 2012),p.87.

[7] L.J.Chen: Travel Behavior Analysis of Urban Residents in Public Transport(MS., Beijing Jiaotong University, China 2008), p.52.

[8] L.H.Huang: An Analysis of Hong Kong Transit City (China Architecture \& Building Press, CHN 2014), p.278.

[9] Z.R.Zhang: Modern Art and Design, Vol. 145 (2005) No.5, p.08.

[10]Z.Qu: Study to Big Station Management Pattern Under Advanced Public Transportation Systems of China (MS., Harbin Engineering University, China 2007), p.14. 